\title{
INTRODUCTION
}

\section{Crossing thresholds in regional climate research: synthesis of the IPCC expert meeting on regional impacts, adaptation, vulnerability, and mitigation}

\author{
Neil Leary ${ }^{1, *}$, Kristen Averyt $^{2}$, Bruce Hewitson ${ }^{3}$, Jose Marengo ${ }^{4}$ \\ ${ }^{1}$ Dickinson College, PO Box 1773, Carlisle, Pennsylvania 17013, USA \\ ${ }^{2}$ University of Colorado at Boulder, NOAA-Western Water Assessment, Earth System Research Laboratory, \\ 325 Broadway, Boulder, Colorado 80305, USA \\ ${ }^{3}$ University of Cape Town, Private Bag X3, Rondebosch 7701, South Africa \\ ${ }^{4}$ CPTEC/INPE, Rodovia Dutra km 40, 12630000 Cachoeira Paulista, São Paulo, Brazil
}

\begin{abstract}
Contributions of regional scale climate change research to the management of climate risks were explored at a meeting of researchers, policymakers, and practitioners in June 2007 (convened by the Task Group on Data and Scenario Support for Impact and Climate Analysis of the Intergovernmental Panel on Climate Change). Although existing knowledge is already being used to inform a wide variety of decisions in multiple contexts, there remain significant knowledge gaps that hamper effective climate-risk management, particularly at the interfaces of different spatial and temporal scales of analysis and cross-system interactions. In this Introduction we synthesize discussions of such knowledge gaps, and highlight recommendations for user-oriented research that produces and communicates information that is credible, defensible, and actionable for climaterisk management.
\end{abstract}

KEY WORDS: Climate change $\cdot$ TGICA $\cdot$ Risk management

\section{Research for managing climate risks}

Substantial advances have been made in the scientific understanding of anthropogenic climate change, the risks it poses to people and ecological systems, and response options for mitigation and adaptation (IPCC 2007a,b,c). The accumulated knowledge in these fields provides a sound foundation for international agreements and national policies in confronting climate change. However, effective risk-management decisions at regional scales are being hampered in many places by lack of information at relevant spatial and temporal scales, low confidence in regional projections of future climate, and other uncertainties. Many of the critical knowledge gaps lie at the interfaces of different spatial and temporal scales of analysis, and of cross-system interactions of physical, ecological, and human systems.

The gaps are being narrowed by research on regional climate, impacts, adaptation, and vulnerability; this is on the road to supplying - or in some cases has already supplied - reliable information, at finer spatial and temporal scales and for system interactions, that is actionable for adaptation measures and other decisions at regional and local scales. In June 2007 the IPCC Task Group on Data and Scenario Support for Impact and Climate Analysis (TGICA) convened an international meeting of researchers, policymakers, and practitioners to explore needs for-and innovative approaches to-interdisciplinary research aimed at providing regional and local information for the manage- 
ment of climate risks (henceforth referred to as 'the meeting' $)^{\mathbf{1}}$. The meeting had 6 objectives:

(1) To identify and explore innovative research approaches for dealing with multi-scale issues and crosssystem processes that are relevant to climate change impacts, adaptation, vulnerability and mitigation;

(2) To foster dialogue among researchers from different fields of climate change research (the climate system; biophysical and human system impacts, adaptation and vulnerability; and mitigation), as well as relevant stakeholder communities;

(3) To explore the complexities arising from the combination of multiple climatic and non-climatic stressors;

(4) To engage a growing community of scientists active in observation and modelling of global and regional scale changes in Earth and human systems; climate change and climate variability impacts, adaptation, and vulnerability; climate change mitigation; environment and sustainable development linkages; and related areas of research;

(5) To identify the ways in which the TGICA can continue to facilitate research, including greater access to observational and model data;

(6) To recognize and prepare for future needs of the IPCC, the Data distribution Centre (DDC) and related avenues of data dissemination, and the community-atlarge.

Attended by more than 40 invited participants, the meeting consisted of extensive small and large group discussions, panel sessions, keynote talks, and poster presentations; 10 of the papers from the meeting are published in this special issue of Climate Research. A proceedings volume with all the presented papers is available from the IPCC (www.ipcc.ch/pdf/supporting-material/tgica_reg-meet-fiji-2007.pdf). In this introduction, the co-chairs and organizers of the conference present a synthesis of key themes and recommendations that emerged from the meeting.

\section{Engaging users and communicating knowledge}

An overarching theme that emerged from the meeting is the importance of improving communication between the science community and society. Better communication is needed to match information (as opposed to data) emanating from the research community to users' needs, to incorporate users' knowledge in research and decision-support analysis, and improve

${ }^{1}$ The meeting was co-sponsored by the global change SysTem for Analysis, Research and Training (START) and the Pacific Center for Environment and Sustainable Development at the University of the South Pacific (PACE/USP), and hosted by PACE/USP on 20-22 June 2007 in Nadi, Fiji. users' understanding, interpretation, and application of tailored information for effective risk management decisions. Users, in this context, include analysts, managers, planners, and decision makers in the public and private sectors who act to manage climate-related risks at levels ranging from local to national to international. They include members of exposed and at-risk communities, including traditional indigenous communities, journalists and other knowledge transfer intermediaries, and members of the public at large. Users can also include researchers who require data and knowledge from others as inputs to their own research.

Science that intends to inform users and be applied in risk management decisions needs a coherent communication strategy. The communications need to be multidirectional so that research considers users' needs and knowledge, users gain access to relevant scientific knowledge in forms that are understandable and applicable to the decisions that they face, and the process produces knowledge that is viewed as credible and legitimate by researchers and users alike.

There are many barriers to effective communication of climate information. These include the complexity of the issues, incomplete information, and uncertainties; different information needs, capacities, and languages of different audiences; multiple sources of information with potentially conflicting messages; and other salient and urgent problems that compete for the time and attention of audiences. Messages that emphasize consequences that are many decades in the future, that are largely negative, or that give little information about feasible response options tend to be ignored.

These barriers can be overcome by developing a communication strategy at the start of a program or project, by including persons in the project team who are skilled in knowledge transfer, and by allocating adequate financial resources to communication issues. Communication can be more effective when it provides opportunities for feedback from intended audiences and takes into account their current knowledge, concerns, decision contexts, and information needs. Effective communication also gives careful attention to the choice of media, format, language, and message that are appropriate, accessible and actionable for a targeted audience. The appropriate approach will vary depending on the purposes, scope, and resources for a particular program, as well as the capacities, interests, and needs of relevant stakeholder constituencies. Generally, there is a need for enhanced dialogue between researchers and user-communities, and greater collaboration between producers and users of information. Engaging users in the framing of research questions early in the process is an important first step. Involvement of users in the design and evaluation of communication materials is also good practice. Common to all 
these elements is the principle of enabling users-i.e. enhancing their capacity - to engage in the interpretation and understanding of communicated information, with full cognizance of caveats and context.

Some research programs have gone further and engaged users at multiple points throughout the research process as sources, co-producers, and evaluators of relevant knowledge who contribute directly to the research endeavour. Although this more intensive, participatory approach to the engagement of users is resource- and time-consuming, the payoff is potentially large. Advantages of participatory approaches to climate-change research and assessment include (1) empowering the participants to make informed personal decisions and to participate in public decisions that can reduce their risks; (2) accessing knowledge not otherwise available to the researchers, leading to a more complete framing and analysis of the problem; (3) targeting research more effectively to produce information that is actionable by users; (4) providing greater transparency in the research process, which increases the credibility and legitimacy of the research results among stakeholders; and (5) increasing the likelihood that the research will be used and result in actions that reduce risk.

Engagement and communication with traditional communities, and use of traditional knowledge, warrants special consideration. Traditional communities can be among the most vulnerable to climate change, and have a compelling need for improved knowledge and other resources for managing and adapting to climate-related risks. Members of traditional communities can have intimate knowledge of past variations in climate, the sensitivity of natural systems to climate variations, and the ways their livelihoods and wellbeing are affected by climatic and environmental variations. They can also have knowledge of risk management strategies that are adapted to their specific social, cultural, economic, and environmental circumstances.

Incorporating this knowledge in research (with the consent and for the benefit of traditional communities), engaging members of traditional communities in research, and communicating research-generated knowledge that is actionable by traditional communities are made challenging by a variety of factors. Language is a key constraint, both in terms of the technical lexicon in which scientific information is commonly communicated, and because traditional and non-traditional communities often have different first languages. Additional hurdles include poor understanding by the research community of the context in which traditional communities live; a lack of formal education of many members of traditional communities; concerns among traditional communities of their traditional knowledge being stolen; and different perspectives about the attributes that confer credibility, validity, and legitimacy to knowledge. Nevertheless, the need is great for engaging traditional communities in processes of knowledge exchange and co-production that can reduce climate risks, and examples of effective collaborations of this sort are needed.

Ultimately, the goal is to communicate a message that is (1) credible (as recognisably a possible and realistic outcome), (2) defensible (in that there is a clear process-based understanding of the response of the physical and social systems to climate and other pressures), and, at the end of the day, that is (3) actionable (the information address the needs of the users, is understandable to them, and is scientifically robust).

\section{Uncertainty and confidence}

Uncertainty, as scientifically understood, is an everpresent component in projecting future climate, but in itself does not preclude confidence in scientific results. Uncertainty is a problematic term, often leading users to conclude erroneously that little is known or understood about the drivers of change, system behaviour, consequences, and feasible response options. This has vexed both researchers and users. Confidence, while not the complete opposite of uncertainty, refers to the degree to which a user may rely on a message. Scientific statements about climate change can be characterized both in terms of the degree of confidence and degree of uncertainty that are attached to them by knowledgeable experts.

Researchers generally take pains to point out the caveats with regards to their results, noting uncertainties that are introduced by data quality problems, methodological difficulties, untested assumptions, and other sources. But the poor communication of what scientists formally understand as uncertainty results in users not always understanding the limitations, sometimes placing undue confidence in simulations of future conditions despite the caveats, while at other times rejecting valid and potentially useful information as insufficiently substantiated to be actionable. In turn, researchers cannot be knowledgeable about all sources of uncertainty that may influence their results, and users may have information to contribute to a more complete and valid assessment of uncertainty. The IPCC (2007a) chapter on regional climate change raised the concept of robust messages, that is, messages which while uncertain in some respects have a core message that is robust on the basis of scientific evidence.

Greater attention is thus needed for communicating such information between researchers and users in forms that are understandable and useable. Users often operate in contexts in which decisions have to be 
made, even if available information is known to have significant deficiencies. To make effective decisions, users need improved understanding of confidence levels and understanding of the uncertainties associated with the information that they use, along with tools to help bound the range of plausible futures, assess qualitative likelihoods, and assign quantitative probabilities.

Dialogue between users and researchers has brought attention to these needs and is slowly leading to progress in developing necessary tools. Users require both qualitative and quantitative tools for interpreting and representing uncertainties to inform decisions that are robust for a range of potential scenarios. Qualitative, non-probabilistic approaches to representing uncertainties with climate envelopes constructed from ensemble projections of multiple climate models are being developed and warrant exploration.

Quantitative, probabilistic approaches also show promise. While the methods are experimental and in need of improvement and validation, the development of probabilistic approaches is a critically important area for collaborative research that can make direct contributions to improved management of climate change risks. Extension of the approach to integrated frameworks is needed to trace uncertainties that cascade from social and economic development paths, to the capacity to mitigate and adapt, to emissions and concentrations of greenhouse gases, to changes in climate, to changes in other Earth systems, to impacts, and back to development paths. Progress in accounting for this cascade of uncertainties would help shed light on questions about the risks associated with exceeding various greenhouse gas concentration levels, the timing of mitigation actions, the participation of large and rapidly growing economies in a new emission reduction regime, and the scale and efficacy of adaptation responses.

\section{System interactions}

The vulnerability of human populations and ecological systems to climate change and variability depends on processes and interactions of multiple systems that are complex, non-linear, incompletely understood, quasi-deterministic, and exceedingly difficult if not impossible to predict. Reflecting this complexity, interdisciplinary and systems-oriented approaches are more commonly applied in climate research than in most other areas of scientific inquiry. Yet practice falls short of where it needs to be.

Researchers typically work most directly with others in the same or closely associated disciplines. Boundaries for research projects often are narrowly drawn to focus on a single system or small number of closely related systems. Observational evidence of system interactions to study and test causal relationships is limited. This leads to the neglect of feedbacks, couplings and cascading effects between social and biophysical systems that have the potential to amplify, dampen, or fundamentally alter system responses. Some research and assessment efforts have attempted to remedy this situation by conducting broadly integrative studies. But these are rare relative to the need, and too often finite resources, time constraints, and lack of researchers with skills to work at disciplinary boundaries have limited cross-disciplinary or crosssystem collaborations to mere transfer of data with little opportunity for joint production of new approaches and knowledge.

Progress will require multidisciplinary research efforts that target cross-system and cross-scale interactions and that investigate climate change within a context of multiple stresses. Research that integrates natural and social sciences and applies a framework of coupled human-environment systems is critical. Of particular priority for research is identifying couplings among Earth systems where feedbacks may amplify climate change, such that risk-exceeding thresholds are crossed and systems are abruptly tipped into fundamentally changed states with continental to global ramifications. Examples include carbon cycle feedbacks, cloud feedbacks, ice sheet dynamics, land surface interactions with atmosphere and climate, deep ocean connections to nutrient cycles and the atmosphere, and ocean acidity. Also of priority are couplings between biophysical and human systems that can impact food security, access to water and sanitation, human health, natural hazards, energy, and economic and human development.

\section{Climate information}

Global-scale changes in climate will manifest themselves as changes in average climate conditions; changes in variability at daily, seasonal, interannual, decadal, and other time scales; and changes in extremes, all of which will exhibit substantial spatial variation. The temporal and spatial patterns of change will be critical determinants of climate risks, in particular as regards exceedence of thresholds of vulnerability. Participants in the meeting observed that climatemodeling efforts have generally failed to provide information about future climate with temporal and spatial resolutions needed by users, and have neglected aspects of climate that have important implications for decision making. General Circulation Models (GCMs) traditionally focus on time horizons that are 
distant relative to most planning horizons and simulate climate at spatial resolutions that are too coarse for assessing vulnerabilities and planning adaptation responses at regional and local scales. The climate data that have been archived from GCM experiments, processed into data products, and disseminated have been selected primarily for understanding climate dynamics and making inter-comparisons of models, with little weight being given to the data needs of end-users. The participants of the meeting called for a paradigm shift in the climate-modeling community to one which gives greater emphasis to the needs of users, and which produces climate-data that is more directly applicable to risk-management decisions in terms of temporal scales, spatial scales, and variables.

\section{Time scale}

Climate projections typically extend up to a century-and sometimes more-into the future, and data products derived from GCM projections emphasize changes in seasonal means averaged over multiple decades. The emphasis on long time horizons and multi-decade averages reflects the temporal scales for which GCMs are considered to be skilled. In contrast, many users are most interested in shorter time horizons that extend a season to a few years, or to one or maybe 2 decades into the future. Reflecting these tendencies, climate-risk reduction and planning efforts generally have relied to a greater degree on historical data of climate variability and trends than on model projections of climate change (see Ziervogel \& Zermoglio 2009, this Special). Where they have used out- puts of climate models, often these are seasonal projections.

Users need information that can help them anticipate climate variability and change over multiple time horizons, ranging from the very near term to multiple decades. For some regions, such as where there are connections to El Niño Southern Oscillation (ENSO) variability, seasonal forecasting skill has developed to levels that can be of significant value to users, and have been applied in areas such as farm management and famine warning. Further research and refinement of methods and tools for seasonal forecasting are likely to yield important benefits in regions where this technique is feasible. Projecting climate variability at decadal time scales is an emerging area of research that, if successful, would find important applications in risk management and planning. Also needed are techniques or frameworks that enable users to compare projections for short, medium, and long-term time horizons, as well as with data for historical variations and trends, for purposes of evaluating the viability of nearterm adaptation measures for continued effectiveness in the future.

\section{Spatial scale}

The coarse-scale resolution of GCM projections have been useful for characterizing, in general terms, the potential impacts of climate change. However, planning adaptive responses that will be effective at reducing risks requires regional and local-scale information about exposures and vulnerabilities to climate stresses. Techniques have been developed to 'downscale' the

Table 1. Attributes for robust downscaling of climate data

\begin{tabular}{|ll|}
\hline Attribute & Comment \\
\hline Variance & $\begin{array}{l}\text { A downscaling procedure should represent both variance from local-scale processes and from } \\
\text { large-scale synoptic forcing. } \\
\text { The degree to which local feedbacks may modulate any downscaled response is a critical question } \\
\text { that should inform the choice of downscaling approach. } \\
\text { This may be an important factor potentially undermining the value of a product. Downscaling } \\
\text { products should assess and demonstrate low vulnerability to stationarity in a given context. }\end{array}$ \\
Multi-model spread & $\begin{array}{l}\text { Multiple-model realizations of the future should be sampled. Of special importance is the issue of } \\
\text { decadal-scale variability, where one forcing model may be sampled at a particular phase of its in- } \\
\text { ternal natural decadal variability, and in so doing misrepresent the larger long-term signal of change. }\end{array}$ \\
Spatial-temporal cohesion & $\begin{array}{l}\text { The capability of a downscaling procedure to reflect spatial auto-correlation between downscaled } \\
\text { locations, and the temporal sequencing of the downscaled data, should be examined where this is a } \\
\text { factor, for example in landscape hydrological response to climate change. }\end{array}$ \\
Envelopes and probability & $\begin{array}{l}\text { Downscaling should attempt to capture the outer limits of projected change and, if possible, char- } \\
\text { acterize the probability distribution of potential changes. } \\
\text { Resource constraints, data availability, data quality, and computational capabilities may limit the } \\
\text { practicality of meeting all the preceding attributes for a robust downscaling; thus the attributes } \\
\text { should be prioritized with respect to the context and purpose of the application to guide the choice } \\
\text { of method. }\end{array}$ \\
\hline
\end{tabular}


coarse resolution GCM projections to finer spatial scales and produce regional scenarios that correspond to, and are consistent with, the GCM projections.

Two downscaling approaches have emerged as the most common: nesting a regional climate model (RCM) within a GCM, and empirical, or statistical, downscaling. Both approaches have strengths and weaknesses, as outlined in IPCC (2007a), yet may be considered to be of comparable skill. The regional climate models dynamically simulate changes in the regional climate in response to large-scale forcings, as simulated by a GCM experiment, taking into account interactions with regional scale features and processes. Using RCMs for downscaling is well documented in the literature, but requires a significant level of technical skill and computational capacity. For these and other reasons, RCMs are typically not viable for one researcher to adopt and explore the range and envelope of possible future climates across multiple GCM forcings. Statistical downscaling approaches use empirically estimated relationships between large-scale forcings and the regional climate to downscale GCM projections. These approaches lend themselves to rapid implementation with nominal computation requirements, and have an extensive literature.

The way that RCMs and statistical downscaling are implemented has the potential to significantly influence the quality of the final product, hence it is incumbent on both the producers and recipients of downscaled climate data to understand the limitations and strengths of a particular implementation. There is a need for inter-comparison and evaluation of downscaled climate data and downscaling practices to help identify the most appropriate downscaling practices. Participants in the meeting agreed that user needs and the utility of downscaled products for decision-making by local and regional entities should be weighed in the evaluation of downscaling. Discussions at the meeting produced a set of attributes and related questions that should be considered in seeking to implement a robust downscaling, which are summarized in Table 1.

\section{Variables of interest}

The most readily accessible outputs of climate models are monthly or seasonally averaged variables such as temperature and precipitation (in time series or averaged for pre-determined time slices of 20 to $30 \mathrm{yr}$ ). These variables are not always directly applicable to the assessment of vulnerabilities or for decision-making for the management of climate risks. Users are often equally-or more-concerned with changes in phenomena such as the timing of onset or cessation of the rainy season, duration of the rainy season, length of dry spells, and frequency, severity, and spatial distribution of extreme events as they are in changes in seasonal means of temperature and precipitation. Greater communication and collaboration is needed among climate modelers, researchers studying impacts, adaptation, and vulnerability, and end-users to identify climate variables that are of interest.

The research community, facilitated by the TGICA, has begun to compile an extensive list of variables needed by the impacts and adaptation community in order to generate useful information (see report of the proceedings of the meeting). The preliminary list has been communicated to relevant organizations and initiatives which will be generating data to use as a basis for much of the IPCC's 5th Assessment Report. The IPCC 3rd and 4th Assessment Reports are being examined to identify potentially relevant variables. These efforts should be supplemented by mechanisms to reach the wider research community and end-user communities. Possible mechanisms include survey instruments, regional meetings that include researchers and users, and meta-analyses of impacts, adaptation, and vulnerability studies to identify commonly used variables. This effort should also expand to include variables pertinent to the social sciences.

\section{Socioeconomic information}

Research on climate-change impacts, adaptation, and vulnerability requires information about past and current social and economic conditions, correlated with climatic and environmental data, to investigate empirically the causes of vulnerability to climate stress, the consequences of exposures, and the efficacy of adaptive strategies that have been used in the past. Information about future social and economic conditions, or socioeconomic scenarios, is needed to examine future impacts, adaptation, and vulnerability. Mitigation research is also dependent on past data and future scenarios of social and economic conditions.

Working with social and economic data poses a number of difficulties for climate change researchers. Multiple entities are involved in the collection of socioeconomic data for multiple purposes, with the result that the variables collected, the protocols for collection, and the definition of variables are not uniformly standardized. The collected data are aggregated for administrative units of varying size and character, often accessible only for national aggregations, and very rarely are the original data spatially referenced. This has made it difficult to construct international datasets with comprehensive, consistent information about key determinants of vulnerability and capacities to adapt and mitigate that can be correlated with spatially 
gridded climate and environmental data. As a result, efforts to identify who is exposed and who is vulnerable are severely hampered. Improving this situation would greatly benefit research in this area.

Studies of future climate change impacts have often used the SRES scenarios, which are the socioeconomic scenarios that were developed by IPCC to generate greenhouse gas emission projections for input to GCM experiments (Nakicenovic \& Swart 2000). This has been done to achieve consistency between climate change analyses and assessments of their potential impacts. However, much as the GCM climate projections are too coarse for use in adaptation and vulnerability research, the SRES scenarios are also insufficiently detailed. There are 3 specific difficulties.

(1) The scenarios provide projections of social, economic and other variables for highly aggregated regions and do not provide data for nation states, much less for sub-national units that are relevant to risk management. Broad mitigation and adaptation policies and objectives may be set at national or even international levels, but many decisions and actions occur at the level of sub-national and local administrative units and individual institutions and actors. This requires information about climate, social, economic, and other variables at finer spatial resolutions than is provided by the SRES scenarios and GCM generated climates.

(2) The set of variables for which projections are available from the SRES are insufficient to model changes in exposures, capacities to act, or vulnerability. These characteristics of populations, which are critical for managing risks, are dependent on demographic, social, health, economic, governance, cultural, environmental, and other variables that are far more extensive than provided by SRES.

(3) The generalized storylines (narrative description of how the future may evolve) that underlie the SRES scenarios do not reflect national and local aspirations and visions of the future. For example, development plans in China call for increased economic development and settlement in the semi-arid, western interior of the country. The achievement of this goal, and the means by which this is achieved, will significantly affect China's vulnerability to climate change, and must be a factor in China's adaptation planning; however, it is not a factor in SRES storylines.

As a consequence of these difficulties, many case studies of vulnerability and adaptation have used scenarios constructed from regional and local considerations that are not readily reconciled with global scenarios used to drive climate change projections. How can scenarios based on local experience be developed in a manner that allows coordination with global scenarios? Sub-global scenarios based on broad rationale, assumptions and outcomes of agreed global scenarios should be developed, but should allow for sub-global deviation where needed. These scenarios also need to be informed by regional, national, and local understanding and information. Some of this information has the potential to change the global scenarios, so there needs to be a 2-way street between the regional and the global scenario development processes. Such an initiative will require substantial resources, innovative tool development, and consultation among regional stakeholders, including modelers, decision makers, and users.

\section{Capacity building and mainstreaming climate change}

The need for capacity building, as a means for mainstreaming climate change adaptation and mitigation, was a recurrent theme throughout the conference. At the most basic level, there is a need for increased awareness and literacy among the general public visà-vis climate change-its causes, the risks it poses to people and the things people value, strategies for reducing the risks, and the benefits, costs, and other consequences of different courses of action. Populations that are particularly vulnerable need an understanding of the contributing factors that create their vulnerable condition, with an objective of empowering people with information and tools to improve their situation. Analysts, managers, planners, and decision makers-acting in areas as diverse as agriculture, water management, public health, emergency preparedness, poverty reduction, urban planning, and economic development-need information about climate risks and risk-management options, the capabilities to interpret and apply this information, and the appropriate decision support tools. Scientific communities need human and institutional capacity in order to execute transdisciplinary research, undertake regional and local risk assessments and decision-support research, and implement effective communication strategies.

The capacity building discussions at the meeting emphasized the needs of developing countries, where needs are greatest. A variety of approaches have been applied to build climate-change-related capacity in developing countries, including outreach programs to raise awareness; training workshops for government leaders, young scientists, professionals, educators, and journalists; and fellowships, grants for research and assessment projects, and regional conferences, networks, and centers. Particularly effective for building science-capacity have been comprehensive programs that emphasize learning by doing through participation in collaborative, interdisciplinary research or assessment projects that are supported with training, 
networking, and technical assistance. An example is the IPCC sponsored Assessments of Impacts and Adaptations to Climate Change (AIACC; www.aiaccproject. org), which produced more than 100 peer-reviewed publications and enabled participants to initiate a number of follow-on projects. Successful programs such as this warrant replication and expansion.

Existing centers of excellence for climate-change research, assessment, and education represent valuable resources for enabling the mainstreaming of climate risk management. Investments in these centers to raise their capabilities, link them with similar centers, engage them with user communities, and orient them to more user-focused research and communication can make them effective resources in their regions for the improvement of risk management. Useful functions that could be performed by regional centers include collecting, producing, interpreting, and disseminating data products; sharing of information about options and best practices for adaptation and mitigation; developing decision support tools; providing access to scientific literature; hosting and training visiting scientists; implementing communication and training programs; coordinating regional research and assessment efforts; advising on adaptation and mitigation projects; integrating climate change into K-12, undergraduate, and graduate education curricula; and leveraging resources to support regional initiatives.

\section{This CR Special}

The studies published in this issue were originally presented as posters at the meeting in Nadi in 2007. Collectively they explore a number of the themes that were the focus of the meeting and that are reported in this paper. But they do not encompass the full range of issues. For that, the reader is directed to the proceedings report.

Ziervogel \& Zermoglio (2009, this Special) examine the use of climate scenarios for decision-making by interviewing agricultural development practitioners and donors working in Africa. They find that climate change projections are rarely used to guide agricultural development projects or planning; practitioners and donors rely instead on historical climate data to characterize variability and extremes and, occasionally, use seasonal forecasts. Some of the factors they find that contribute to this state of affairs include coarse spatial and temporal resolution of the climatemodel scenarios; poor representation by the models of critical aspects of regional climate variability; climate model outputs that have little potential for direct application in agricultural decisions; data that are difficult to access; lack of computational and technical capabili- ties to use climate model outputs, and poor communication between the modelling and user communities. The authors recommend a shift away from a 'supply driven' process to a 'user-focused' process that bridges gaps between climatologists and users to provide 'actionable' climate information.

Tadross et al. (2009, this Special) provide an example of how indicators of local climate variability (constructed from observational data, correlations of the indicators with larger scale variability, and comparisons with climate change projections) can be used in combination to inform farm-management decisions. Using daily rainfall data from $>100$ stations in southern Africa, they construct indicators of the onset, cessation, and duration of the rainy season, that are directly relevant to decisions about when to plant, what cultivar to plant, and whether to store water for the end of the growing season. Past trends in the indicators are identified and show that the rainy season is starting later, ending sooner, and decreasing in duration over northern parts of their study region. The authors find correlations of the indicators with ENSO and the Antarctic Oscillation, indicating a potential for using large-scale climate modes to forecast changes in the indicators in some areas. The indicator trends are also compared with empirically downscaled projections of climate change from 7 GCMs for the period 2046-2065. The results indicate that reliance on recent trends is not a robust strategy for adapting to longer-term climate change.

Vescovi et al. (2009, this Special) relate the knowledge transfer experience of Ouranos, a consortium of government agencies and universities in Canada that coordinates climate change research in Quebec. It represents one possible model for building capacity for mainstreaming climate change adaptation and mitigation through a regional, distributed network of multiple institutions. Ouranos enables direct links among climate scientists, researchers on climate-change impacts, adaptation and vulnerability, and authorities responsible for adaptation decisions. These linkages are used for multidirectional communication that informs research priorities and questions, the question of the relevant spatial and temporal scales, and the treatment of uncertainties. Their greatest challenge has been knowledge transfer regarding uncertainties. They have found indicators of vulnerability and adaptive capacity to be an effective means of communicating different and uncertain futures that are readily understood by user groups. In one of the examples they present, a pressure-state-response framework that was used to develop indicators of climatic pressure and social vulnerability to communicate public health risk from high temperature events for different areas of Quebec and different scenarios of the future. Results 
have been mapped in a GIS (geographic information system) to communicate areas of particularly high vulnerability in the province.

Confalonieri et al. (2009, this Special) and Aguilar et al. (2009, this Special) present 2 parallel, but different, approaches to the measurement of the vulnerability of populations to climate change. Both construct vulnerability as functions of socioeconomic, climatic and environmental factors that interact to yield spatially varied patterns of vulnerability. Confalonieri et al. (2009) map the vulnerability of the population of Brazil to adverse health outcomes from diseases that exhibit sensitivity to climate variations. They construct an indicator of vulnerability from 3 sub-indices for socioeconomic, epidemiological, and climatological vulnerability. Aguilar et al. (2009) develop a general indicator of vulnerability for people living in the south-central coastal plain of El Salvador that also has 3 components. In this case the sub-indices measure exposure to climatic stresses, the resilience of the population for living and coping with stress, and the capacity of the population to adapt to their changing environment. Values for the subindices and vulnerability indicator are calculated for the years 2004 and 2015. For the future case, projections of future policies made by the government of El Salvador for compliance with monitoring of the Millennium Development Goals are use to project future values of social and economic variables that compose the sub-indices for resilience and adaptive capacity. The importance of understanding how vulnerability may change under current planning goals of the national government took precedence over enforcing consistency with global scenarios of social and economic change.

Podesta et al. (2009, this Special) model the consequences of a potentially drier climate for risk-averse farmers at 2 sites in the Argentine Pampas for 3 different cases: the 'naïve' farmer (who does not recognize and therefore does not react to the changed climate); the 'clairvoyant' farmer (who is perfectly aware of the changes and optimizes consistent with the new conditions); and delayed adaptation, in which the farmer responds with a lag to changes in the climate. The drier climate scenario is analyzed not because it is considered most likely, but in response to stakeholders who have voiced concern that-because the agricultural system in marginal parts of the region evolved partly due to a trend of increasing rainfall in the latter half of the 20th century-the system may not be economically sustainable if the climate reverts to a drier state. The modelling approach uses the DSSAT (Decision Support System for Agrotechnolgy Transfer) framework, but employs a value function for farmeroptimizing behavior that incorporates risk aversion. For a study site located in a relatively humid part of the Pampas, the drier climate has minor effects on eco- nomic returns or the risk of negative profits. But for the more marginal site, economic returns are sharply reduced and the risk of negative profits increases for the 'naïve' farmer case. When adaptation is included, much of the adverse impact is offset.

Nunn (2009, this Special) examines the state of preparedness of the Pacific Islands for managing and adapting to the risks of global climate change. Sea level rise is one pressure acting on Pacific Island communities, but vulnerability to sea level rise is not homogeneous in the Pacific Islands and there are other equally important climate, social, and economic stresses at work. A number of factors make it challenging for the Pacific Islands to respond to climate change in an effective and sustainable way. A pervasive view that climate change is caused by outsiders and should be solved by outsiders, strong political incentives for decision makers to give precedence to short term economic growth over other concerns, a strong sentiment favoring the rights of private landowners over public purposes, lack of enforcement of environmental legislation, lack of understanding of climate related problems, and comparatively few members of government or other organizations with scientific or technical training related to climate change and risk management all combine to prevent action to adapt to climate change. Nunn recommends that climate-change awareness be mainstreamed in these countries and that communitylevel decision makers be empowered with knowledge and tools to act.

La Rovere et al. (2009, this Special) present an example of a strategy that integrates both adaptation and mitigation for Northeast Brazil. The region is semiarid, is chronically affected by drought, has the lowest income per capita in the country, and is one of the most vulnerable regions in Brazil. Producing biodiesel from vegetable oils has the potential to reduce the vulnerability of small family farmers, since certain oilproducing crops are tolerant of low rainfall, and production of these crops can help diversify family income. Production of biodiesel by small farmers is being promoted in Brazil as part of a national program to displace diesel oil with biodiesel, which has the potential benefit of reducing carbon dioxide emissions. However, there are institutional, social, economic and technical capacity barriers to be overcome if the program is to successfully engage small farmers as sustainable suppliers of biodiesel. The authors discuss measures to overcome these barriers.

Koo et al. (2009, this Special) use a Regional Climate Model (RCM) to dynamically downscale fine resolution climate change response patterns over Korea. The study reveals the issues involved in implementing dynamical downscaling, and shows the added value of regional spatial detail that can be achieved. The study 
investigates some of the dynamic response attributes beyond the base spatial anomalies of mean temperature change, and considers attributes of projected change such as the distribution function of daily temperatures, temperature extremes, changing vertical temperature profiles, and humidity. A key message implicit in the work is that the development of downscaled regional information should be partnered with an investigation of the climate dynamics that give rise to the change, and in this way increase the robustness of the conclusions reached. The study illustrates an approach that can be used to support adaptation actions.

Peter et al. (2009, this Special) use a Bayesian approach to explore the complexities surrounding land use and biofuels in South Africa. The study points out the cross-scale and inter-sector dependencies that characterize activities within society, and the consequent uncertainties that arise. Using Bayesian networks the authors develop a framework to explore the integrated nature of water, food, and energy - the context within which biofuel development occurs-and the climate change influences on these interactions. Through the testing of different land use strategies with climate change scenarios, the results disclose key sensitivities of biofuel production and the complexities of assessing limits to growth. The model that is presented provides a valuable approach to analyzing the robustness of national biofuel production plans.

\section{Conclusions and recommendations}

Substantial progress has been made in scientific understanding of observed changes in the Earth's climate; the contributions of human and other forces to the observed changes; the qualitative character and quantified range of possible future changes; the consequences of climate change; options for mitigating and adapting to climate change; and the benefits, costs, and other consequences of these actions. The accumulated knowledge is being used to inform a wide variety of decisions in multiple contexts. However, user needs for information that is relevant and directly applicable to risk management decisions at local to regional scales are not being met.

Discussions at the IPCC Expert Meeting on Regional Impacts, Adaptation, Vulnerability and Mitigation highlighted a number of reasons for this failure and explored possible remedies. A fundamental shift to a more user-oriented focus is needed, with the goal of providing actionable information for adaptation and mitigation decisions. Success will require greater attention to communication between climate researchers; researchers of climate-change impacts, adaptation, vulnerability, and mitigation; users; and affected popu- lations. Participatory models for research and assessment are effective at producing actionable information and warrant wider adoption. Knowledge gaps that are important for risk-management decisions and are priorities for focused research are found at the interfaces of different temporal and spatial scales of analysis and cross-system interactions. Users need information at finer temporal and spatial scales than is commonly provided. Couplings between human systems and biophysical systems are critical determinants of vulnerability, but research is hampered by inadequate social and economic data that are comparable across jurisdictions and that can be spatially correlated with climatic and environmental data. Advances are needed in the understanding and communication of uncertainties, and in decision-support tools to help with making decisions under conditions of uncertainty. Progress will require investments to increase the capacities of research and user communities to collaborate with each other to advance, interpret, communicate, and apply knowledge about climate change risks and risk management strategies that is credible, defensible, and actionable.

Because the meeting was convened by the TGICA, discussions frequently touched on recommendations for the TGICA and the IPCC. The meeting did not formally endorse a set of recommendations, but the following suggestions are consistent with the general sense of the discussions:

- The TGICA should explore options for facilitating the development and effective dissemination of downscaled climate projections that meet high scientific standards, and for providing access to downscaled products to researchers and users through the DDC. Suggestions made at the meeting include development of standards and guidance documents for downscaling and using downscaled products, convening regional meetings of experts from research and user communities, and helping to initiate intercomparison studies of downscaling.

- The TGICA should continue its efforts to identify and communicate to the climate modeling community climate variables, time scales, and spatial scales that are most relevant for impacts, adaptation, and vulnerability research. The effort should be expanded to encompass information needs of end-users.

- The TGICA should explore options for facilitating the development and dissemination of regional scale datasets and future scenarios of socioeconomic information. There is a need for regional and local data products that integrate and spatially reference socioeconomic, climatic and environmental databoth historical data and projections of the futureand that can be related to global-scale scenarios that are used to drive GCM experiments. 
- The TGICA should explore options for facilitating access by researchers and users to studies and examples of adaptation.

- The IPCC should develop and implement a more comprehensive and extensive communication strategy that emphasizes communication of climatechange risks and risk management responses.

\section{LITERATURE CITED}

Aguilar MY, Pacheco TR, Tobar JM, Quiñónez JC (2009) Vulnerability and adaptation to climate change of rural inhabitants in the central coastal plain, El Salvador. Clim Res 40:187-198

Confalonieri UEC, Marinho DP, Rodriguez RE (2009) A national assessment of public health vulnerability: towards a novel approach potentially applicable to tackle climate change impacts in Brazil. Clim Res 40:175-186

IPCC (2007a). Climate change 2007: the physical science basis. In: Solomon S, Qin D, Manning M, Marquis M, Averyt K, Tignor M, Miller H, Chen Z (eds) Contribution of Working Group I to the 4th Assessment Report of the Intergovernmental Panel on Climate Change. Cambridge University Press, New York

IPCC (2007b) Climate change 2007: impacts, adaptation and vulnerability. In Parry M, Canziani O, Palutikof J, van der Linden P, Hanson C (eds) Contribution of Working Group II to the 4th Assessment Report of the Intergovernmental Panel on Climate Change. Cambridge University Press, New York

IPCC $(2007 \mathrm{c})$ Climate change 2007: mitigation of climate change. In: Metz B, Davidson O, Bosch P, Dave R, Meyer L (eds) Contribution of Working Group III to the 4th Assess- ment Report of the Intergovernmental Panel on Climate Change. Cambridge University Press, New York

Koo GS, Boo KO, Kwon WT (2009) Projection of temperature over Korea using an MM5 regional climate simulation. Clim Res 40:241-248

La Rovere EL, Avzaradel AC, Monteiro JMG (2009) Potential synergy between adaptation and mitigation strategies: production of vegetable oils and biodiesel in northeastern Brazil. Clim Res 40:233-239

Nakicenovic N,Swart RH (eds) (2000) Emissions scenarios. A Special Report of Working Group III of the Intergovernmental Panel on Climate Change. Cambridge University Press, New York

Nunn PD (2009) Responding to the challenges of climate change in the Pacific Islands: management and technological imperatives. Clim Res 40:211-231

Peter C, de Lange S, Musango JK, April K, Potgieter A (2009) Employing Baysian modelling to climate change impacts on biofuel production interdependencies. Clim Res 40: 249-260

Podestá G, Bert F, Rajagopalan B, Apipattanavis S, Laciana C, Weber E, Easterling W, Katz R, Menendez DLA (2009) Decadal climate variability in the Argentine Pampas: regional impacts of plausible climate scenarios on agricultural systems. Clim Res 40:199-210

Tadross M, Suarez P, Lotsch A, Hachigonta S and others (2009) Growing-season rainfall and scenarios of future change in southeast Africa: implications for cultivating maize. Clim Res 40:147-161

Vescovi L, Bourque A, Simonet G, Musy A (2009) Transfer of climate knowledge to a regional climate-change management body to support vulnerability and impact assessments and adaptation measures. Clim Res 40:163-173

Ziervogel G, Zermoglio F (2009) Challenges and opportunities in using climate change scenarios for developing adaptation strategies in Africa. Clim Res 40:133-146 